\title{
Viewing the Anti-Social Personality Transformation of School Bullying Victims from the Perspective of Experimental Analysis
}

\author{
Kan Huang \\ Department of Police Management, Sichuan Police College, Luzhou, China \\ Email address: \\ hk198548@hotmail.com \\ To cite this article: \\ Kan Huang. Viewing the Anti-Social Personality Transformation of School Bullying Victims from the Perspective of Experimental Analysis. \\ Psychology and Behavioral Sciences. Vol. 8, No. 2, 2019, pp. 55-60. doi: 10.11648/j.pbs.20190802.14
}

Received: May 17, 2019; Accepted: June 12, 2019; Published: June 15, 2019

\begin{abstract}
School bullying is on the rise around the world. The phenomenon of school bullying is a microcosm of the social environment, which means that the bullying phenomenon in the school can be magnified to the whole society, inducing and presenting as a crime, so it must be studied, controlled and prevented. In this paper, horizontal and vertical comparisons were made in the three dimensions of bullies, victims and irrelevant personnel, so as to study and analyze the psychological status of victims by means of scale measurement, and then reveal the relationship between victims and their own anti-social personality. Students from three different middle schools in X city, S Province were randomly selected as the research objects, who had finished the questionnaires of Middle School Bullying Questionnaire, Chinese Big Five Personality Inventory Brief Version, and Anti-social Screening Questionnaire Self-evaluation version. The current bullying situations were obtained through data analysis; significant differences were found in the dimensions of neuroticism, conscientiousness, agreeableness, and extraversion among bullies, victims, and non-bullied; therefore, it was concluded that the bullying victims and their anti-social behavior tendencies were in positive correlation; school bullying had severe impacts on the social activities and personality formations of the victims. The results have provided the theoretical basis for the research on personality building of adolescent victims of school bullying.
\end{abstract}

Keywords: Adolescent, Bullying, Victim, Anti-Social, Personality Disorder, Relationship

\section{Research Background}

Over the years, school bullying incidents have occurred repeatedly, which has aroused widespread concern in the community. The most concerned school bullying incidents often occur in junior high schools, whose students are in adolescence. The socialization of adolescence is the most basic and the most important stage in the process of human socialization. In addition, school is one of the environments where adolescents spend most of their time; it is the most frequent and important place for interpersonal communication among adolescents. school bullying not only involves the interpersonal interactions but also affects the value orientations, behavioral patterns, and role definitions of adolescents. Being frequently bullied, students would suffer from emotional depression, loneliness, insomnia, distraction, poor academic performances, weariness of study, self-esteem decline, etc., which brings psychological damages to the victims and has severe negative impacts on the personalities of the victims, all of these are adverse to the mental and physical developments of adolescents.

The anti-social personality disorder (ASPD) refers to the personality disorder characterized by inconformity in personal behaviors and the social norms; ASPD patients often show a general behavior pattern that ignores or infringes on the rights and interests of others, such as disobeying social norms, cheating, being aggressive, being irresponsible, refusing to repent, etc. Therefore, ASPD patients would endanger public security and bring losses to the social economy [1]. The main difference between ASPD and other abnormal personalities is that ASPD sprouts in childhood and adolescence; the most important period of ASPD development is the adolescence, in which the behavioral characteristics of ASPD patients show obvious anti-social behavior tendencies with long-term social adjustment disorders [2]. Adolescents are relatively more sensitive, and their emotions are often undulate, oppositional, and suspicious, etc. Research has indicated that the anti-social behavioral trait is a 
kind of long-term and stable personality trait; individuals with such personality tendencies would treat others indifferently, lack the sense of guilt, and show unplanned behaviors; thus, it easily induces the individual behaviors of aggression and bullying. The anti-social behaviors of individuals with highly anti-social behaviors are more serious, stable, and aggressive in their childhood and adolescence. Both domestic and foreign research has found that the school bullying is related to the personalities of students [3-6]; it has indicated that the emotions of school bullying victims are unstable and impulsive, which are especially sensitive to external stimuli such as the pressure stimuli that cannot be relieved timely. school bullying greatly affects the personality characteristics of adolescent students. Therefore, in such a special growth period, the mental and physical health of adolescents need more attention from the public, thereby their comprehensive development in personalities could be promoted and the school bullying could be stopped.

We found surprising associations with bullying and anti-social personality were found, and may even lead to a vicious cycle. From the perspective of bullies, it is often a variety of factors that lead to personality disorders to impose bullying behavior; But for the victims, because of the pressure of bullying behavior, they often feel that there is no way out, and try to use violence against violence, tit-for-tat, further promote and form the anti-social personality, and implement new bullying and even violent behavior.

\section{Research Methods}

\subsection{Research Objects}

Students from 3 different middle schools in $\mathrm{X}$ city, $\mathrm{S}$ Province were randomly selected as the research objects. The random sampling method was applied to select a total of 250 students from junior grades ( 3 grades in total), with 130 boys and 120 girls; a total of 250 copies of questionnaires were issued, and 225 copies were received, with a recovery rate of $90 \%$.

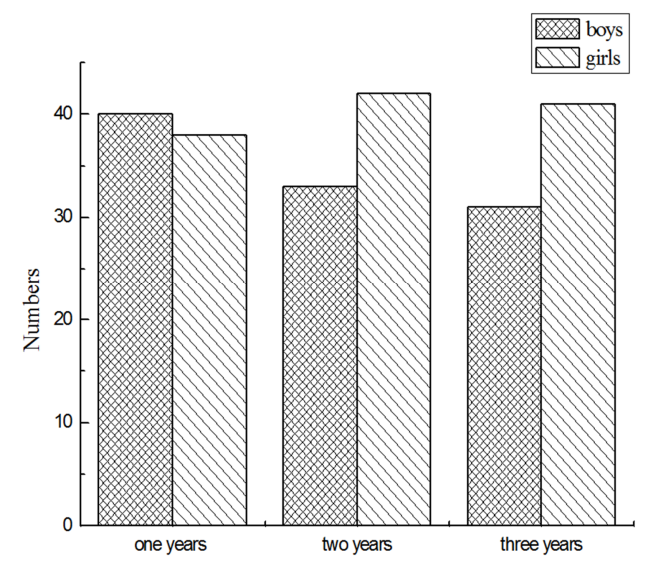

Figure 1. The sample of the middle school.

The basic information of the students involved in the research was as follow: (1) A total of 104 boys and 121 girls were involved, and the number of boys and girls was basically balanced; (2) 78 students were from the first grade of junior high schools (junior 1), 75 were from the second grade of junior high schools (junior 2), and 72 were from the third grade of junior high schools (junior 3). The composition of the sample was shown in Figure 1.

\subsection{Research Tools}

(1) Middle School Bullying Questionnaire [7]. The questionnaire included 2 sub-questionnaires, i.e. the Bullying Questionnaire and the Bullied Questionnaire. The Bullying Questionnaire had a total of 13 questions in the dimensions of physical bullying, verbal bullying, and relational bullying. The questionnaire used quinary score system, i.e. 1 (never), 2 (rare), 3 (occasional), 4 (frequent), and 5 (always); the higher the score was, the more serious the bullying was. The Cronbach's alpha of the questionnaire was 0.91 .

(2) Chinese Big Five Personality Inventory Brief Version (CBF-PI-B). The questionnaire was the Chinese Big Five Personality Inventory Brief Version (CBF-PI-B) proposed by Wang et al. [8] based on the Big Five personality traits; it included 40 questions from the dimensions of neuroticism $(\mathrm{N})$, conscientiousness $(\mathrm{C})$, agreeableness $(\mathrm{A})$, openness $(\mathrm{O})$, and extraversion (E). Each dimension included 8 questions, which balanced the statistical indicators and the question contents to cover the conceptual frameworks of the original complete version [9]. The questionnaire used senary score system, i.e. 1 (completely non-conformed), 2 (mostly non-conformed), 3 (some non-conformed), 4 (some conformed), 5 (mostly conformed), and 6 (completely conformed). The questionnaire had preferable reliability and validity. In specific, the Cronbach's alpha coefficient was from 0.764 (agreeableness) to 0.814 (neuroticism); in addition, the Cronbach's alpha coefficients of the five dimensions were above 0.75 , the neuroticism was 0.81 , and the extraversion was 0.80 , the conscientiousness was 0.81 , the openness was 0.78 , and the agreeableness was 0.76 ; the average Cronbach's alpha coefficient of the five dimensions was 0.793; the retest coefficient of the 10-week-interval was from 0.672 (agreeableness) to 0.811 (openness), with an average of 0.742 ; besides, the correlation coefficient with other Big Five personality questionnaires was significant at 0.01 .

(3) Personality Diagnostic Questionnaire-4 (PDQ-4). The questionnaire could assess 12 types of personality disorders (including the paranoid personality disorder, the schizoid personality disorder, the schizotypal personality disorder, the anti-social personality disorder, the psychopathy, the borderline personality disorder, the histrionic personality disorder, the narcissistic personality disorder, the avoidant personality disorder, the dependent personality disorder, the passive-aggressive personality disorder, and the obsessive-compulsive personality disorder), with 107 items in total.

The sub-scale of anti-social personality disorder was applied [10]. The anti-social sub-scale consisted of 3 dimensions, i.e. ruthlessness, narcissism, and impulsiveness, with 20 items in total. Each item used triplex score system, i.e. 0 (completely incorrect), 2 (some correct), and 3 (completely correct); the higher the score was, the higher the anti-social 
personality tendency of the adolescent was. The Cronbach's alpha of the sub-scale was 0.82 , and the Cronbach's alpha coefficients of all 3 dimensions were from 0.81 to 0.85 .

\subsection{Statistics Analysis}

The researchers were the consultants; before the issuance of the questionnaires, the anonymity and the confidentiality of the questionnaires should be emphasized; in addition, the results could be back-fed to individuals as needed to accelerate the participation of students [11-13]. The time for answering the questionnaires was 20 minutes, and all the copies were collected after students had finished. The SPSS 20.0 statistics software was applied to analyze and process the data obtained from the questionnaires, including the variance analysis and the correlation analysis to obtain the relations among indicators.

\section{Research Results and Discussions}

\subsection{Role Distribution of Middle School Students in School Bullying}

Table 1 showed the role composition in school bullying of the research. It was seen that the bullies were 8 in total, which accounted for $3.5 \%$ of the total samples; the victims were 52 in total, which accounted for $23.1 \%$ of the total samples; the outsiders (non-bullied) were 164 in total, which accounted for $72.8 \%$ of the total samples. Therefore, the investigation indicated that about $26.6 \%$ of the students were involved in bullying incidents. In addition, the victims occupied $23.1 \%$.

Table 1. Role distribution in school bullying.

\begin{tabular}{|c|c|c|c|c|}
\hline Roles and proportions in school bullying & Junior 1 & Junior 2 & Junior 3 & Total \\
\hline Bullies & 2 & 3 & 3 & 8 \\
\hline Proportion of bullies & $2.5 \%$ & $4 \%$ & $4 \%$ & $3.5 \%$ \\
\hline Victims & 27 & 17 & 8 & 52 \\
\hline Proportion of victims & $34.7 \%$ & $25.5 \%$ & $11.1 \%$ & $23.1 \%$ \\
\hline Non-bullied & 49 & 53 & 62 & 164 \\
\hline Proportion of non-bullied & $62.8 \%$ & $70.6 \%$ & $85.9 \%$ & $72.8 \%$ \\
\hline Total & 78 & 75 & 72 & 225 \\
\hline
\end{tabular}

Research results showed that of all the students who participated in the research, the bullies were 8 in total, which accounted for $3.5 \%$ of the total samples; the victims were 52 in total, which accounted for $23.1 \%$ of the total samples; the outsiders (non-bullied) were 164 in total, which accounted for $72.8 \%$ of the total samples. Therefore, the investigation indicated that about $26.6 \%$ of the students were involved in bullying incidents. In addition, the victims occupied $23.1 \%$. The data indicated that bullying was relatively common in middle schools.

\subsection{Analysis of Personality Variance of Bullies, Victims, and Non-Bullied}

The variance analysis of the Big Five personality traits of bullies, victims, and non-bullied was shown in Table 2. It was seen from Table 2 that in addition to the dimensions of openness and conscientiousness, significant differences were found in other personality traits among the bullies, victims, and non-bullied, in which the differences in neuroticism was the most significant $(\mathrm{F}=6.621, \mathrm{Df}=2, \mathrm{P}<0.001)$.

Therefore, it was concluded that the victims of bullying are impulsive and unstable in emotions.

Table 2. Analysis of personality variance of bullies, victims, and non-bullied.

\begin{tabular}{llllll}
\hline Personality dimensions & Sum of squares & D $\boldsymbol{f}$ & mean squared error(MSE) & $\boldsymbol{F}$ & 6.621 \\
N & 15.023 & 2 & 5.013 & 2.761 & 0.000 \\
E & 6.558 & 2 & 2.185 & 3.999 & 0.041 \\
C & 9.493 & 2 & 3.159 & 2.279 & 0.009 \\
O & 8.414 & 2 & 2.837 & 0.069 \\
A & 8.329 & 2 & 2.771 & 3.871 \\
\hline
\end{tabular}

\subsection{Multiple Comparative Analysis of Personality Dimensions of Bullies, Victims, and Non-Bullied}

Table 3 showed the results of the Big Five personality traits of different students. Table 4 showed the comparative analysis of the Big Five personality traits of different students.

Table 3. Results of Big Five personality traits of different students.

\begin{tabular}{|c|c|c|c|c|c|c|}
\hline Students & Results & $\mathbf{N}$ & $\mathbf{E}$ & $\mathrm{C}$ & $\mathbf{O}$ & $\mathbf{A}$ \\
\hline \multirow{2}{*}{ Bullies } & $\mathrm{M}$ & $3.34 \pm$ & $3.53 \pm$ & $3.61 \pm$ & $3.49 \pm$ & $3.51 \pm$ \\
\hline & SD & 0.977 & 0.641 & 0.826 & 1.077 & 0.590 \\
\hline \multirow{2}{*}{ Victims } & $\mathrm{M}$ & $3.31 \pm$ & $3.54 \pm$ & $3.74 \pm$ & $3.70 \pm$ & $3.91 \pm$ \\
\hline & $\mathrm{SD}$ & 0.921 & 0.727 & 1.007 & 0.971 & 0.944 \\
\hline \multirow{2}{*}{ Non-bullied } & $\mathrm{M}$ & $2.69 \pm$ & $3.89 \pm$ & $4.15 \pm$ & $4.07 \pm$ & $4.01 \pm$ \\
\hline & SD & 0.849 & 0.930 & 0.866 & 1.076 & 0.841 \\
\hline
\end{tabular}


Table 4. Multiple comparative analysis of Big Five personality traits of different adolescents.

\begin{tabular}{lllllll}
\hline Students & & N & E & C & O & A \\
\hline \multirow{2}{*}{ Non-bullied } & Bullies & -0.372 & 0.301 & 0.347 & 0.372 & $0.637^{*}$ \\
& Victims & -0.519 & 0.201 & -0.017 & 0.141 & 0.195 \\
\multirow{2}{*}{ Bullies } & Non-bullied & 0.372 & -0.301 & -0.347 & -0.372 & $-0.637^{*}$ \\
& Victims & -0.145 & -0.099 & -0.378 & -0.237 & -0.441 \\
\multirow{2}{*}{ Victims } & Non-bullied & 0.519 & -0.201 & 0.017 & -0.141 & -0.195 \\
& Bullies & 0.145 & -0.099 & 0.347 & 0.237 & 0.441 \\
\hline
\end{tabular}

Note: $p<0.05, *<0.01 ; * *<0.001, * * *<0.0001$.

It was concluded from the results of One-way ANOVA in Table 3 that significant differences were found among the 5 dimensions. It was concluded from the multiple comparative analysis in Table 4 that a significant difference was found in the agreeableness of non-bullied and victims of school bullying. In addition, significant differences were found in the dimensions of neuroticism, extraversion, and conscientiousness of non-bullied and victims of school bullying. Therefore, it was inferred that the emotions of both bullies and victims were unstable, who also showed the tendencies of anti-social personalities that ignored the benefits and feelings of others and did not mind having conflicts with others; students with such behaviors would be more likely to come down with the anti-social personality disorders.

\subsection{Differentiated Tests of Personality Dimensions of Victims and Non-Bullied}

The differences in personality tendencies of victims and non-bullied were obtained through statistical analysis and were shown in Table 5. Significant differences were found in the 5 dimensions of victims and non-bullied, as shown in Table 5. In terms of the dimensions of conscientiousness, agreeableness, and openness, the results of non-bullied were significantly higher than that of the victims, i.e. the non-bullied students were more amiable, friendly, enthusiastic, and responsible. In addition, the dimensions of neuroticism and extraversion of the victims were higher than that of the non-bullied, which indicated that the emotions of the non-bullied were stabler than that of the victims; in addition, the victims of school bullying were more likely to be trapped in the negative emotions due to the poor capability of emotion adjustment, who would frequently feel angry, depressed, or shy, and would cover themselves while interacting with others; in general, the bullying victims were of strong awareness of self-defense and were bad at contacting with the outside world.

Table 5. Differentiated tests of personality dimensions of different roles.

\begin{tabular}{|c|c|c|c|c|c|c|}
\hline Personality dimensions & Gender & $N$ & $M$ & SD & $t$ & $p$ \\
\hline \multirow{2}{*}{$\mathrm{N}$} & Victims & 51 & 2.83 & 0.970 & \multirow{2}{*}{$2.172^{*}$} & \multirow[t]{2}{*}{0.028} \\
\hline & Non-bullied & 164 & 2.70 & 0.818 & & \\
\hline \multirow{2}{*}{ E } & Victims & 51 & 3.69 & 0.910 & \multirow{2}{*}{$-2.459^{*}$} & \multirow[t]{2}{*}{0.013} \\
\hline & Non-bullied & 164 & 3.88 & 0.854 & & \\
\hline $\mathrm{C}$ & $\begin{array}{l}\text { Victims } \\
\text { Non-bullied }\end{array}$ & $\begin{array}{l}51 \\
164\end{array}$ & $\begin{array}{l}3.62 \\
4.19\end{array}$ & $\begin{array}{l}0.953 \\
0.762\end{array}$ & $-5.037^{* * *}$ & 0.000 \\
\hline $\mathrm{O}$ & $\begin{array}{l}\text { Victims } \\
\text { Non-bullied }\end{array}$ & $\begin{array}{l}51 \\
164\end{array}$ & $\begin{array}{l}3.74 \\
4.02\end{array}$ & $\begin{array}{l}1.093 \\
1.043\end{array}$ & $-3.519^{* *}$ & 0.001 \\
\hline A & $\begin{array}{l}\text { Victims } \\
\text { Non-bullied }\end{array}$ & $\begin{array}{l}51 \\
164\end{array}$ & $\begin{array}{l}4.31 \\
4.01\end{array}$ & $\begin{array}{l}0.776 \\
0.812\end{array}$ & $-4.358^{* * *}$ & 0.000 \\
\hline
\end{tabular}

Note: $p<0.05, *<0.01 ; * *<0.001, * * *<0.0001$.

\subsection{Correlation Analysis of Anti-Social Behavior Tendency of Victims and Non-Bullied}

Table 6 showed the average, standard deviation, and correlation matrices of the anti-social behavior tendencies among the bullying victims and non-bullied. The anti-social personality tendency was in significant positive correlation with the bullying victims and was in significant negative correlation with the non-bullied.

Table 6. Correlation analysis of anti-social behavior tendency of victims and non-bullied.

\begin{tabular}{lllll}
\hline Variables & $\boldsymbol{M}$ & SD & $\mathbf{1}$ & \\
\hline Anti-social behavior tendency & 0.61 & 0.20 & & \\
Non-bullied & 1.80 & 0.54 & $-0.21 * *$ & \\
Victims & 1.47 & 0.43 & $0.45^{* *}$ & $0.42^{* *}$ \\
\hline
\end{tabular}

Note: $p<0.05, *<0.01 ; * *<0.001, * * *<0.0001$.

\subsection{Analysis of Relations Among Personalities of Victims, Bullies, and Non-Bullied}

The research found significant differences in the 4 dimensions of neuroticism, conscientiousness, agreeableness, and extraversion of bullies, victims and non-bullied. In addition, the differences in neuroticism dimension were the most significant. The bullying behaviors of middle school 
students were significantly related to the 5 dimensions of the Big Five personality traits; in addition, the neuroticism, extraversion, and conscientiousness dimensions of the victims Bullies and non-bullied were significantly correlated. The results of non-bullied were significantly higher than that of the victims, i.e. the non-bullied students were more amiable, friendly, enthusiastic, and responsible. The research also suggested that the occurrence of bullying was closely related to the stability of emotions of individuals; the middle school students with higher neuroticism tendencies would be more impulsive and have stronger reactions toward the outside stimuli, whose angry emotions were more than other students, thus the school bullying was more likely to occur on them, they would become either a bully or a victim; on the contrary, students with lower neuroticism scores would have fewer troubles with stable emotions, whose psychological fluctuations were less, thereby the possibility of school bullying was low. Therefore, personality would directly affect the occurrence of school bullying, and the occurrence of school bullying was closely related to the stability of emotions of adolescents. In addition, the research also found that the victims of school bullying were more likely to be trapped in the negative emotions due to the poor capability of emotion adjustment, who would frequently feel angry, depressed, or shy, and would cover themselves while interacting with others; in general, the bullying victims were of strong awareness of self-defense and were bad at contacting with the outside world.

\subsection{Correlation Analysis of anti-Social Behavior Tendency of Victims}

In terms of adolescents, the higher their anti-social behavior tendencies were, the higher the possibility of school bullying was, i.e. the adolescents with higher anti-social behavior tendencies were more likely to be attacked and insulted by others at school, or they were more likely to disobey the regulations of schools. The anti-social behavioral characteristics included impulsiveness, narcissism, and ruthlessness, which were the core personality traits that led to the offensive behaviors of adolescents. Due to the characteristics of being irritable, indifferent, lack of guilty senses, incapable of feeling empathy for others, lack of emotional experiences, and indifferent to others, in the case of conflicts and contradictions, the individuals with anti-social personalities would solve the problems through verbal, physical, and relational abuses. The research found a significant positive correlation between anti-social behavior tendencies and the victims of bullying. The general pressure theories considered that while being in the anxious situations, adolescents would have the bullying, attacking, or violent behaviors and/or negative avoidant behaviors if their pressures cannot be relieved or abreacted in time. The ignorant abuse, being excluded by peers, and being bullied in childhood were the components of harmful or stimulating pressure sources, which made individuals have negative emotions; therefore, adolescents would respond to the pressures with bad or violent behaviors. The typical personality characteristics of bullies often included high tendency of neuroticism, self-centered, indifferent emotions, impulsive emotions, and strong reactions to the outside stimuli; the typical personality characteristics of bullying victims often included low self-esteem, anxiety, depression, and inferiority. Therefore, once the bullying victims (individual factor) were involved in bullying (environmental factor), if they failed to relieve or abreact the pressures brought by these stimuli, the negative emotions would generate, leading to anti-social personality disorders.

\section{Conclusion}

The analysis of school bullying among middle school student and their bullying behaviors have suggested significant differences in the personality dimensions of bullies, victims, and non-bullied. The anti-social tendencies and non-bullied were in significant negative correlation; while the anti-social tendencies and bullying victims were in significant positive correlation. Therefore, it is concluded that bullying victims are more likely to generate anti-social tendencies in school bullying. Based on the perspective of victims, the psychological changes of school bullying victims need major concerns; their anti-social personality disorder should be constrained before its formation. In addition, the actions against school bullying are more important. Victims of school bullying are often cowardly and are bad at dealing the interpersonal relationships; their characteristics are often introverted; therefore, even if they are suffering from school bullying, they would be unwilling to talk to their classmates, teachers, and parents. Therefore, in daily lives, parents need to communicate with their kids in time to establish good parental relationships that their kids can trust with and talk to. The original family relationship is always the main base of adolescent personality determinacy. The good parental relationships encourage bullying victims to tell their parents at once, thereby the school bullying can be discovered as soon as possible. Besides, schools should investigate the school bullying situations among students on a regular basis to timely screen the possibly occurred, occurred, and occurring school bullying incidents for the timely interferences of teachers with emotional supports, which requires the teachers should not only prevent the students from being bullied but also help students build their healthy and good personalities and qualities, thereby the school bullying and violent incidents could be effectively prevented, and the treatment of school bullying is achieved.

\section{References}

[1] Black D W. The treatment of anti-social personality disorder [J]. Current Treatment Options in Psychiatry, 2017, 4(4), 295-302.

[2] Low S K, Evans C B R, Cotter K L, The association of parental monitoring and peer rejection on anti-social behavior among Malaysian juvenile offenders [J]. Residential Treatment for Children and Youth, 2018, 35 (2): 155-171. 
[3] Velotti P, Elison J, Garofalo C. Shame and aggression: Different trajectories and implications [J]. Aggression and Violent Behavior, 2014, 19 (4): 454-461.

[4] Elison J, Garofalo C, Velotti P. Shame and aggression: Theoretical considerations [J]. Aggression and Violent Behavior, 2014, 19(4): 447-453.

[5] Velotti P, Garofalo C, Bottazzi F, et al. Faces of shame: implications for self-esteem, emotion regulation, aggression, and well-being[J]. The Journal of Psychology, 2017, 151 (2): $171-184$.

[6] Ma F, Chen B, XU F, et al. Generalized trust predicts young children's willingness to delay gratification [J]. Journal of Experimental Child Psychology, 2018, 169: 118-125.

[7] Kolla N J, Dunlop K, Meyer J H. Corticostriatal connectivity in anti-social personality disorder by mao-a genotype and its relationship to aggressive behavior [J]. International Journal of Neuropsychopharmacology, 2018, 21 (8): 725-733.

[8] Wang M C, Chen P Y, Chen F, et al. Preventing school bullying: investigation of the link between anti-bullying strategies, prevention ownership, prevention climate, and prevention leadership [J]. Applied Psychology, 2017, 66 (4): 577-598.
[9] Lmc V D B, Mjn R, Decoene S. Treatment of anti-social personality disorder: development of a practice focused framework [J]. International Journal of Law \& Psychiatry, 2018, 58, 72-78.

[10] Kornienko O, Dishion T J, Ha T. Peer network dynamics and the amplification of anti-social to violent behavior among young adolescents in public middle schools [J]. Journal of Emotional \& Behavioral Disorders, 2017, 26 (1): 106-234.

[11] Longobardi C, lotti N O, Jungert $\mathrm{T}$, et al. Student-teacher relationships and bullying: the role of student social status $[\mathrm{J}]$. Journal of Adolesc, 2018, 63: 1-10.

[12] Kim Y K, Yang M Y, Barthelemy, J J, et al. A binary gender analysis to bullying, dating violence, and attempted suicide: the disproportionate effect of depression and psychological harm [J]. Children \& Youth Services Review, 2018, 90: 141-148.

[13] Rigby K. Bullying in Australian schools: the perceptions of victims and other students [J]. Social Psychology of Education, 2017, 20 (2): 1-12. 